\title{
Control concept for autonomous changeable material flow systems
}

\author{
DR.-ING. MiCHAEL WILKE \\ LEHRSTUHL FÜR FÖRDERTECHNIK MATERIALFLUSS LOGISTIK, TU MÜNCHEN
}

Today's material flow systems for mass customization or dynamic productions are usually realized with manual transportation systems. However new concepts in the domain of material flow and device control like function-oriented modularization and intelligent multiagent-systems offer the possibility to employ changeable and automated material flow systems in dynamic production structures. These systems need the ability to react on unplanned and unexpected events autonomously.

\section{Introduction}

Short innovation cycles, increasing numbers of product variants and advanced technological progress are characterizing the situation of the production companies [Cox-98]. This leads to a rising pressure on time and costs. Often only those competitors can reach benefits who are able to react on changing markets and customer preferences quickly and cost-effectively [Schuh-04]. The customer becomes more and more a co-designer and is asking for individualized products, which fulfil his own needs. A strong increase of product varieties in different product ranges and sectors can be noticed [SFB582-04]. This trend leads to smaller batch sizes and to an increasing number of transportation processes.

The fulfilment of these requirements demands a fundamental redesign of facility structures. [West-03, Wien-02, Wirt-01]. On one hand flexible production structures and changeable material flow systems are needed. On the other hand economies of automation have to be used in order to reduce the costs in relation to series production. Thereby future logistics systems have to feature short reaction times, high flexibility in structures and processes and the ability to react on unexpected events autonomously.

Present automated material flow systems are too inflexible and in case of complex systems they are difficult to control. This leads to high engineering costs and long start-up and alteration times. Therefore in today's dynamic production environments today usually manual material handling systems are used, like stacker and pallet trucks. They possess neither highest productivity nor quantifiable advantages like the zero error strategy or time optimised applications. Furthermore manual transportations cause not only high working costs, but also have a high exposure and sometimes reduced quality [Dull-99].

Thus new automation concepts have to be developed, which allow for operating automated material flow systems cost-efficiently and flexibly in dynamic production structures. A solution lies in the design of autonomous, decentralized controlled materials handling units with standardized interfaces on the physical and on the control level.

The changeability and capability of such modularized material flow system depend on one hand on the capability and flexibility of the single components (load carrying device, means of transport, warehousing technology) and on the other hand on the interaction of these components. Among physical processes like load handling, the technologies for communication and controlling are facing great challenges.

\section{Requirements to a changeable automated material flow system}

In addition to flexibility, which can be seen as the possibility for reacting to changes in preplanned dimensions and scenarios, changeable material flow systems additionally provide the possibility to react to unexpected events. 
Therefore a changeable material flow system has to fulfil the following changeability requirements in order to be able to adjust itself to all, including unplanned, changes [Hand-01, Gün-02]:

- $\quad$ Product flexibility

- Layout flexibility

- $\quad$ Throughput flexibility

These three requirements of flexibility can be summarized as operational flexibility. They can handle production fluctuations and slight alterations of the given product spectrum.

A material flow system which would fulfil these three requirements completely, would be changeable, but not affordable and hardly realizable. Therefore the material flow system has to be upgradeable and, if this is not sufficient, it has to be integrationable, in order to be able to cooperate with other systems directly.

- Upgrade ability:

(upgrade with own-system modules)

- Integration ability:

(upgrade with non-system modules)

The attributes upgrade ability and integration ability give the material flow system the ability to react on unexpected events. This kind of flexibility is called strategic changeability. It is used, if the operative flexibility does not suffice to react on alterations of the product spectrum.

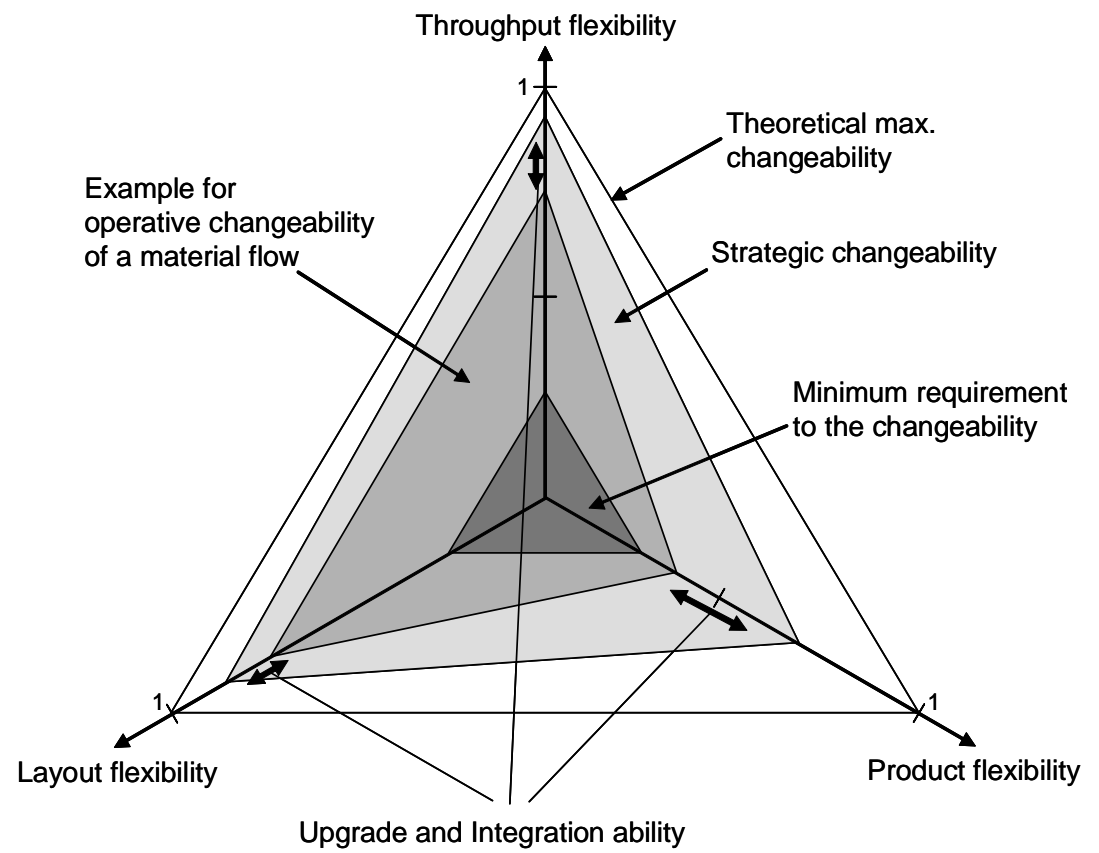

Fig. 1:Rating of the changeability of a material flow system

Whether a material flow system is changeable depends on the design of its components. They have to realize the attributes upgrade and integration ability. For this new solutions for modularization and automation are needed, as described below.

\section{Design Methodology: Function-oriented modularization}

A changeable automated material flow system requires a consequent decentralized modularization, which is including not only the mechanical aspect, but is also providing autonomous and intelligent components on the energetic and control level. A function-oriented modularization provides an adequate methodology for design. The material flow system is assembled from mechatronical modules and the system borders are drawn accordingly to the functionality of the module. 
A module is defined according to the function it has to accomplish. All participants of the material flow system like cranes, vehicles of a monorail overhead conveyer system etc. are representing autonomous mechatronical function units. The definition of the functionality, the capability, the geometry of the module and its interfaces are specified in so called XML-Module descriptions [Wil-06].

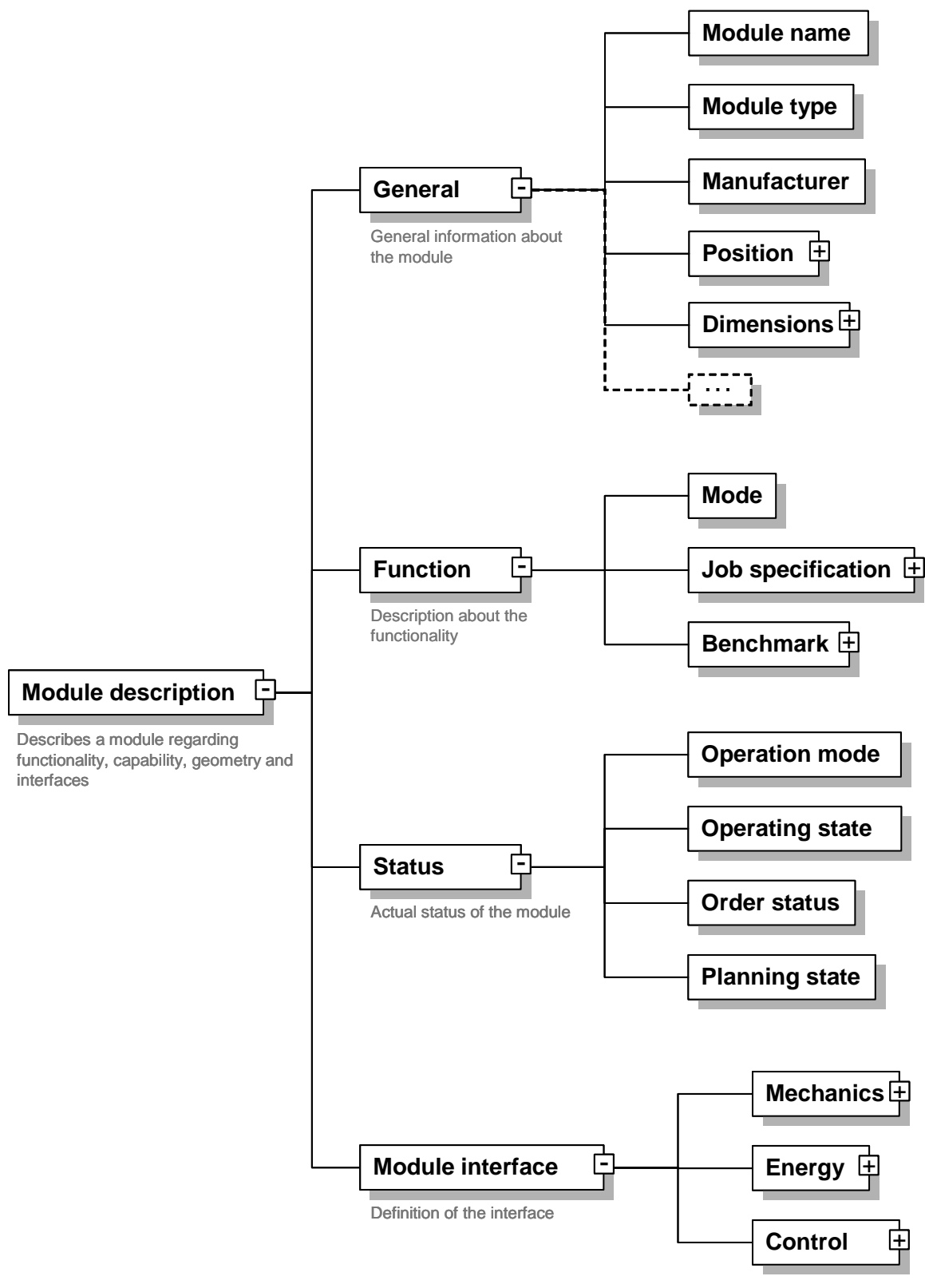

Fig. 2: Schematic structure of the XML-Module description

\section{Communication concept}

In order for modules of different manufacturers to be connected or exchanged in a changeable material flow system, they have to feature standardised, compatible and capable communication interfaces. The interface must also comply with the requirements of future material flow or factory modules, without being explicitly preplanned. Both a horizontal communication between modules and a vertical communication to superior PPS and ERP-Systems should be possible. Analogue to the described requirements to changeability, the communication concept has to obey the characteristics of upgrade and integration ability. 


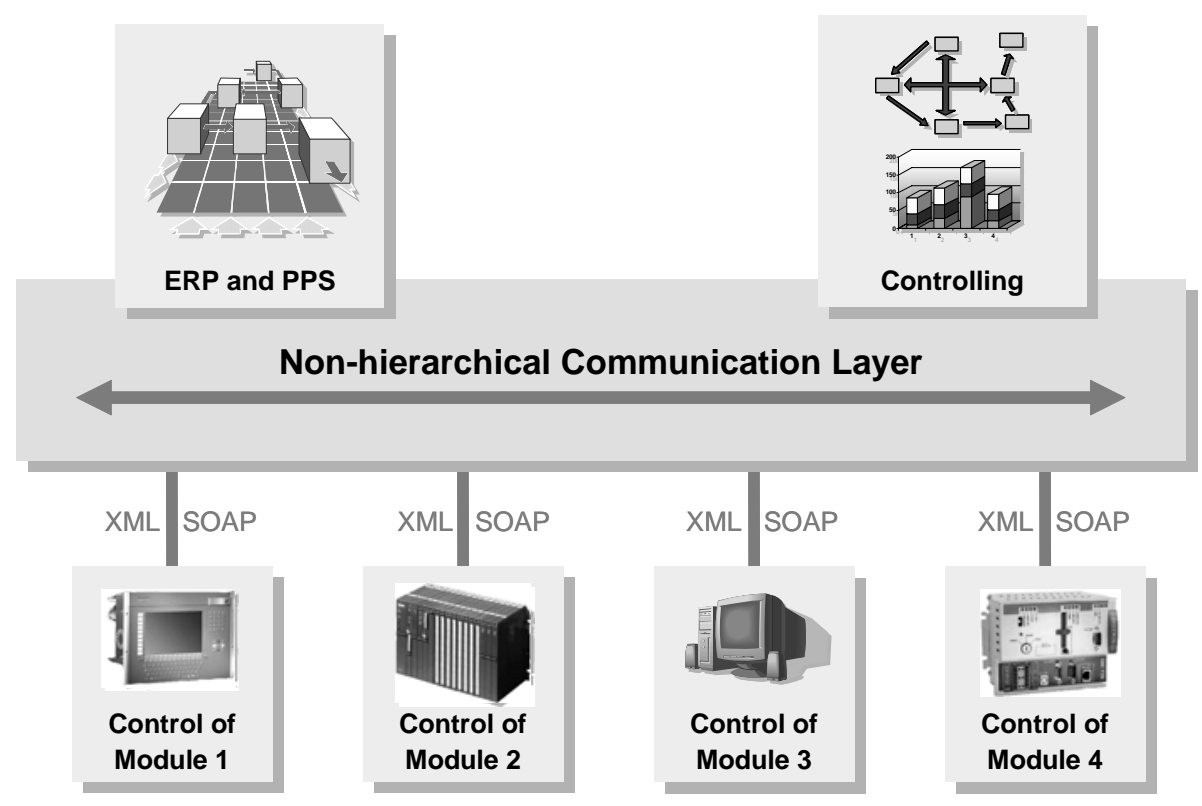

Fig. 3:Communication architecture

The communication concept follows the principle, that modules are controlled decentrally, but are connected via a common non-hierarchical communication layer. All data are generated decentrally. They can be always associated to a certain module, but are available for everyone.

An adequate solution is offered by the data language XML (Extensible Markup Language), which originates in the IT sector. XML is a meta language which describes rules for text based data structures. It allows a definition of the logical meaning of data, information and texts. Besides the actual information the data declaration and the data format are also transmitted at the same time. XML coded data can be easily read and optically formatted through a standard web browser. Data exchange based on XML creates the best conditions for an upgradeable open communication in a changeable material flow system.

\section{Control concept}

The following vehicle control concept for a changeable material flow system has been developed at the chair fml, TU Munich, basing on the changeability requirements, in consideration of the function-oriented modularization of distributed automation and a communication concept based on XML [Wil-06]. For better explanation this control concept will be explained by means of an analogy.

The road network with its drivers can be seen as changeable material flow system. Every driver can reach every place and transport different goods independently from other drivers. For this a driver is planning his path with a roadmap and on his way, he is orientating himself at signposts. In contrast to an automated system it does not matter for him, if he passes two or more junctions or even has to take a detour. He can react to unplanned situations occurring on his way and so he is superior to closed automated systems. His changeability relies on analyzing a roadmap and orientating himself at signposts.

The following newly developed vehicle control concept shows how the behaviour of the driver could be adapted to an automated material flow system (e.g. monorail overhead conveyer), in order to attain the same changeability. First the vehicles need a kind of roadmap. This is a matrix, which contains information about places (transfer stations, switches etc.) are connected by which kind of paths. This matrix is called waypoint matrix. It is the informational reproduction of the material flow system and assumes the function of the common communication layer as described above. It is imaging the layout, the characteristics and actual state (bookings, position of the vehicles etc.) of the material flow system. Thus the waypoint matrix shows not only the static, but also the dynamic state of the system.

The data of the waypoint matrix (coded in XML) is required by all modules (vehicles, switches etc.). Thereby the information is not only read, but also altered by the modules. A vehicle is calculating its path locally and autonomously. Afterwards the path is written to the waypoint matrix via bookings. That allows the vehicles to consider the positions and planned paths of others 
during their path finding without directly communicating. A passing-token procedure assures that each member gets the actual state of the waypoint matrix. Concurring bookings are avoided in principle [Wil-06]. Not only vehicles get their information from the matrix. Also switch modules, which are represented as a waypoint, find out how to switch themselves via the bookings in the matrix.

Besides the waypoint matrix functioning as a roadmap the transportation vehicles need signposts for orientation. These signposts can be realised with RFID-Tags. The tags possess a unique identification number and are mounted beside the trackway. They are marking transfer stations and junctions. They represent the so called waypoints of the waypoint matrix. The vehicles read the tags while passing in order to find out where they are.

\section{Advantages}

This concept offers high layout flexibility. Information about the physical path is saved in only one place: the waypoint matrix. There changes of the topology can be done easily and fast. Even in case of unplanned alterations of the layout, the control programs of the vehicles do not need to be reprogrammed because the vehicles get all necessary information for a decentralised path finding from of the waypoint matrix.

The concept is also highly fail-safe. Vehicles are able to choose alternative paths autonomously, if the planned way is blocked due to failures.

Additionally the concept offers high throughput flexibility. Vehicles can be added or removed at any time without changes to the software of the other vehicles. They do not communicate directly but get all necessary information via the bookings in the waypoint matrix in order to know which way is free or blocked by other participants. So in addition rails can be used in both directions, which allows for taking the shortest route. Vehicles book only the requested driving direction without blocking the track section for the others completely. Thus following vehicles can use the tracks in the same driving direction.

In principle path finding is executed by the vehicle control. Therefore it is possible for vehicles with different strategies and abilities to operate next to each other in the same system. That is being guaranteed by the function-oriented modularization and the waypoint matrix concept.

This control concept for the vehicle controls is upgradeable and integrationable and thereby fulfils the important requirements for changeable automated material flow systems. It is applicable to both electrically operated monorail/overhead crane systems and automated guided vehicle systems. By the strict modularity and the clearly drawn system borders with their standardized mechatronical interface, redundant control procedures and redundant data management are avoided.

In this concept the functionality of the material flow controller (MFC) is reduced to placing transportation orders. Functions like path finding and avoiding traffic jams, which are usually done by the central subsystem controller [VDMA-15276], are undertaken by the vehicles controller.

\section{Conclusion}

Today's material flow systems for dynamic production systems are primarily realized with manual transportation systems. New concepts in the domain of material flow and device controller like the function-oriented modularization and intelligent multi-agents-systems offer the possibility for installing changeable and automated material flow systems in the next years.

The base for realizing a cost-efficient, fail-safe and changeable system is the use of autonomous, decentralized controlled modules with standardized interfaces. Start-up times and alteration times are reduced significantly.

The cooperation of the modules is accomplished by a common, non-hierarchy communication layer based on XML which enables an open upgradeable data exchange both horizontally between material flow modules and vertically from the master level to the device level.

Primary realization and material flow simulations are showing the great potential concerning changeability and capability of such systems. Therefore the chair fml (TU Munich) has developed first solutions. 


\section{Literature}

[Cox-98]

[Dull-99]

[Gün-02]

[Gün-05]

[Hand-01]

[Homp-05]

[Schuh-04]

[SFB582-04]

[VDMA-15276]

[West-03]

[Wien-02]

[Wil-06]

[Wirt-01]

[Zäh-03]
Cox, M.; Alm, R.: The right stuff: America's move to mass customization, Federal Reserve, Bank of Dallas, 1998 Annual Report, S. 3-26,1998.

Dullinger, K. H.: Das Zauberwort heißt Flexibilität - Wie sich Logistikanlagen von vornherein flexibel für zukünftige Anforderungen anlegen lassen. IN: Materialfluss 30(1999)4, S. 15-18.

Günthner, W.A.; Heinecker, M.; Wilke, M.: Materialflusssysteme für wandelbare Fabrikstrukturen. IN: Industrie Management 18(2002)5, S. 8-10

Günthner, W.A.; Wilke, M.: Mit neuen Lösungen $\mathrm{zu}$ wandelbaren Materialflusssystemen. IN: Intelligenter produzieren (2005)4, S. 5-6

Handrich, W.: Flexible, flurfreie Materialflusstechnik für dynamische Produktionsstrukturen (Dissertation). München: Utz Verlag, 2001.

ten Hompel, M; Lammers, W.: Das Internet der Dinge - Die RFIDTechnologie ermöglicht die Selbstorganisation logistischer Prozesse. Ein grundlegender Wandel für den automatisierten Materialfluss

IN: Logistik inside (2004), Sonderheft Who is Who der Logistik 2005, S.118-120.

Schuh, G.; Harre, J.; Gottschalk, S.; Kampker, A.: Design for Changeability (DFC) - Das richtige Maß an Wandlungsfähigkeit finden, Ergebnisse des EU-Verbundforschungsprojektes „Modular Plant Architecture“. IN: wt Werkstattstechnik online 94(2004)4; S. 100-106.

SFB 582: Marktnahe Produktion individualisierter Produkte, http:/www.sfb582.de, TU München, 2004.

Verband Deutscher Maschinen- und Anlagenbau (VDMA): VDMAEinheitsblatt 15276: Datenschnittstellen in Materialflusssystemen. Berlin: Beuth, 1994.

Westkämper, E.; Kirchner, S.; Winkler, R.: Unternehmensstudie zur Wandlungsfähigkeit von Unternehmen. IN: wt Werkstattstechnik online 93(2003)4, S. 245-260.

Wiendahl, H-.P.: Wandlungsfähigkeit $\quad$ - Schlüsselbegriff der zukunftsfähigen Fabrik. IN: wt Werkstattstechnik online 92(2002)4, S. 122127.

Wilke, M.: Wandelbare automatisierte Materialflusssysteme für dynamische Produktionsstrukturen (Dissertation) München: Utz Verlag, 2006

Wirth, S.; Baumann, A.: Wertschöpfung durch vernetzte Kompetenz Schlanke Kompetenzkooperation. München: Huss, 2001.

Zäh, M.; Ulrich, C.; Wagner, W.; Wilke, M.: Reaktionsszenario Minifabrik, IN: wt Werkstattstechnik online 93(2003)9, S. 646-650 